\title{
Environmentally Sustainable Tensioned Fabric Structure in the Form of Half-Costa YZ-Plane
}

\author{
Hafizah M. Azlan, Yee H. Min, and Nurul Afiqah A. Malek
}

\begin{abstract}
Form-finding analysis is carried out and presented for half-Costa tensioned membrane structure model in YZ-plane. There are three models presented, each with different center part of the half-Costa boundaries. Nonlinear analysis method is adopted for the form-finding analysis. Half-Costa tensioned membrane models in YZ-plane with different geometry have been found in a good agreement with least square error of total warp and fill stress deviation. Results obtained from this study would become a reference to select suitable parameters to increase the performance of sustainable tensioned membrane structure in the form of half-Costa in YZ-plane respected to their boundary condition. These resource efficient structures have the ability to prevent further damage to the environment hence these models presented are good selective forms for design engineer and architect to ponder on.
\end{abstract}

Index Terms-Center part, form-finding, half-Costa YZ-plane, nonlinear analysis method.

\section{INTRODUCTION}

Tensioned membrane structures (TMS) are the composition of tensioned membrane as structural members where the fabric patterns tensioned through mechanicals means or cables to a rigid supporting system to provide roofing structure [1]. The fabric of TMS is made from woven or laid yarns that are alternatively pass over and under each other before it is joined by a third diagonal yarn or so called as seam to secure them in place. Additionally, the yarn is made from fibers that are combined in various ways to ensure that it is adequate in length and thickness [2]. The design of structural membrane such as TMS is anticipated with form-finding. Form-finding allows minimal use of the materials and creating structures with attractive and impressive forms. These forms are based on boundary conditions and prescribed pre-stress field. The designing stage will lead to TMS initial equilibrium shape that will allow TMS to act in pure tension. Correspondingly, in this part of designing, the external load is not considered [3]. Membrane structures like TMS has to conform to the minimal surface geometry because the nature of minimal surface that are doubly curved and occupies smallest area within a boundary condition. This properties has led to acknowledge minimal surface area as the most stable area [4]

Manuscript received October 30, 2019; revised January 20, 2020. This work was supported by Universiti Teknologi Mara, Cawangan Pulau Pinang, Malaysia.

The authors are with Faculty of Civil Engineering, Universiti Teknologi MARA, Cawangan Pulau Pinang, Malaysia (e-mail: hafizahazlan86@gmail.com,_yhooimin@yahoo.com, fie.malique@gmail.com).
As stated by [1], TMS is a lightweight structure which weights around 500 to $1500 \mathrm{~g} / \mathrm{cm}^{2}$. It is a high strength structure and able to provide a great variety of surface form. TMS appears to be a sustainable development in energy efficiency as it is able to allow natural light to penetrate with light transmission around 5-20\%. This amount is sufficient to eliminate or reduce the use of artificial lighting during daytime with low absorption of solar energy (4-17\%). [1] adds that TMS has minimal site interruptions since it is fabricated in factories and has lower maintenance in comparison to glass.

[1] have proposed a computational strategies for form-finding using nonlinear analysis method which have been adopted for this study and [1] have determined the initial equilibrium shape of Moebius Strip and Costa minimal surface. Correspondingly, [5] have conducted a study to overcome the inherit weakness of proposed computational strategies incorporating the form-finding of Catenoid, Helocoid, Scherk and Enneper minimal surface. Other forms of minimal surfaces such as Oval and Egg shape have been considered by [6], [7] and Moebius Strip by [8]-[10]. The form-finding of Enneper is taken another look by [11], [12] while other minimal surfaces such as Chen-Gackstatter, Monkey Saddle, Handkerchief, Bour and Thomsen have been studied by [13]-[18]. However, the study on half-Costa in YZ plane with different geometry as TMS form have not been done up till now. Thus, this paper focused on half-Costa TMS model in YZ-plane with different geometry. Therefore, the essential parameter needs to be identified and the analyses have to be carried out. The main concern regarding this form is the boundary condition as a form of TMS which have been the objective of this study.

\section{Half-Costa TMS Model IN YZ-Plane}

Minimal surface is a surface that poses the least area within a boundary which then allows it to be the most stable area. Another factor that causes minimal surface to be stable is due to the fact that more energy needed to change it form. In other words, a physical system will not change its shape unless it can be change easily with less energy [19]. Costa minimal surface is unique because it continues forever in every direction and the shape does not intersect itself [20]. Half-Costa TMS model in YZ-plane emerges from Costa minimal surface that split on its YZ-plane as shown in Fig. 1.

As been mentioned earlier, Costa minimal surface have no boundary. Similarly, half-Costa too has no boundary. That is acceptable in terms of mathematical formulation. However, for engineering application, a structure must be supported, thus requires a defined boundary. In order to apply the idea of 
half Costa TFS model in YZ-plane to an actual fabric structure, the practical issue needs to be overcome.

This minimal shape can be denoted by three equations as follow:

$$
\begin{gathered}
x=\frac{1}{2} R\left\{-\zeta(u+i v)+\pi u+\frac{\pi^{2}}{4 e_{1}}+\frac{\pi}{2 e_{1}}\left[\zeta\left(u+i v-\frac{1}{2}\right)-\zeta\left(u+i v-\frac{1}{2} i\right)\right]\right\} \quad(1) \\
y=\frac{1}{2} R\left\{-i \zeta(u+i v)+\pi v+\frac{\pi^{2}}{4 e_{1}}-\frac{\pi}{2 e_{1}}\left[i \zeta\left(u+i v-\frac{1}{2}\right)-i \zeta\left(u+i v-\frac{1}{2} i\right)\right]\right\}(2) \\
z=\frac{1}{4} \sqrt{2 \pi} \ln \left|\frac{\rho(u+i v)-e_{1}}{\rho(u+i v)+e_{1}}\right|
\end{gathered}
$$

where $\zeta(z)$ is the Weierstrass zeta function, $\rho\left(g_{2}, g: z\right)$ is the Weierstrass elliptic function with $\left(g_{2}, g_{3}\right)=(189.07272 \ldots .0)$ and $\mathrm{e}_{1}=6.87519$ [21], $u$ and $v$ are available. These polar coordinated is used in MATLAB software that represented half-Costa TMS model in YZ-plane with respect to their $\mathrm{x}, \mathrm{y}$ and $\mathrm{z}$ coordinates. All those coordinates presented in MATLAB software is transferred to ADINA software to create half-Costa TMS model in YZ plane with different geometries.

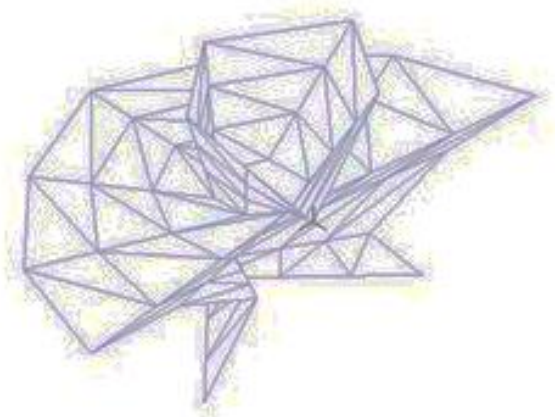

Fig. 1. Half-costa TMZ model in YZ-plane.

\section{Methodology}

\section{A. Form-Finding Using Nonlinear Analysis Method}

Determining the initial equilibrium shape of TMS will require form-finding process which is a function of stress ratio in warp and fill direction. At this stage, the external load is not considered [22], [23]. The analysis carried out by using a method proposed by [1] that will solve initial equilibrium problem and load analysis. These computational strategies involves two phases in a cycle and they are denoted as Phase I and Phase II. It is initiated by Phase I that involves initial assumed shape whereby this shape will be updated before it is continues with the second stage (Phase II). This stage aims to check the convergence of the updated initial assumed shape from Phase I through iterative calculation. After both of these stages are completed, the resultant shape is called initial equilibrium shape. This is because the shape is considered to be in the state of equilibrium under the prescribed warp and fill stresses, only if the difference between the prescribed fabric stresses and the obtained fabric stresses relative to the prescribed stresses are negligibly small. The initial equilibrium shape of tensioned fabric structures corresponds to minimal surfaces as it is solved under condition of equal tension in warp and fill directions. There are three half-Costa TMS model in YZ-plane are proposed in this paper. The height is the same for all models whereby all models have 2.8261 units of height measured from the top to the bottom of the models and a round 1.9307 units of horizontal opening. However, these models are created with different center.

\section{RESUlTS AND DisCUSSION}

\section{A. Model I}

The geometry of half-Costa TMS model can be further divided into three parts which are the top, center and bottom as shown in Fig. 2. This study has focused on the center part whereby these models are represented as Model I, Model II and Model III.

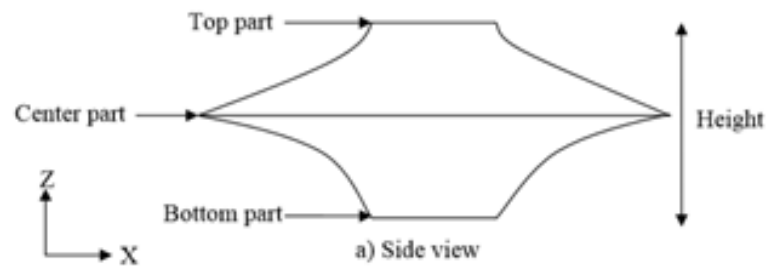

Fig. 2. Different parts of half-costa TMS model.

The form-finding of half-Costa TMS model in YZ-plane with different geometry have been carried out. Total 66 and 108 number of nodes and elements, respectively used to generate half-Costa TMS model in YZ-plane for all models. Since half-Costa is generated from Costa minimal surface that does not have any boundary, the anticlastic feature has not been adopted [1]. The initial assumed shape and initial equilibrium shape of Model I as shown in Table I. Model 1 has a width of 12.499 units of the center part. Based on the graph of total stress deviation in warp and fill direction versus stress analysis stage as presented in Fig. 3 and it is proven that Model I converged.

TABLE I: INITIAL ASSUMED SHAPE AND INITIAL EQUILIBRIUM SHAPE OF

Model I


3D View


Fig. 3. Total stress deviation versus stress analysis stage of Model 1.

\section{B. Model II}

As been mentioned earlier, these three models presented have different center part and Model II is introduced by having more edges compared to Model I that have more edges and the width of the center part is 10.672 units. The initial assumed shape of Model II and its initial equilibrium shape as illustrated in Table II followed by Fig. 4 that shows the graph of total stress deviation in warp and fill direction versus stress analysis stage of Model II.

TABLE II: INITIAL ASSUMED SHAPE AND INITIAL EQUILIBRIUM SHAPE OF

\begin{tabular}{ccc} 
MODEL II & $\begin{array}{c}\text { Initial Assumed } \\
\text { Shape }\end{array}$ \\
\hline YZ-View & $\begin{array}{c}\text { Initial Equilibrium } \\
\text { Shape }\end{array}$ \\
\hline
\end{tabular}

XY-View

\section{Model III}

Model III has the least edges model introduced in this study having a width of 12.482 units of the center part. The initial assumed shape and initial equilibrium shape is viewed by Table III. The convergence of this model is achieved and proved in Fig. 5. Half-Costa TFS model in YZ-plane with different geometries have been studied. The iterative calculation have been carried out to fulfil the convergence criteria of form-finding. The convergence criteria adopted for form-finding using nonlinear analysis method is based on the least square error of the total warp and fill stresses which must be lower than 0.01 . The total stress deviation in warp and fill direction for all models are presented in Table IV.



Fig. 4. Total stress deviation versus stress analysis stage of Model II.

TABLE III: INITIAL ASSUMED SHAPE AND INITIAL EQUILIBRIUM SHAPE OF MODEL III

$\begin{array}{ccc}\text { Model III } & \begin{array}{c}\text { Initial Assumed } \\ \text { Shape }\end{array}\end{array}$


TABLE IV: STRESS DEVIATION IN WARP AND FILL DIRECTION

$\begin{array}{llll}\text { Total } & \text { Model I } & \text { Model II } & \text { Model III } \\ \text { Stress } & & \end{array}$

Deviation

\begin{tabular}{lccc}
$\begin{array}{l}\text { Warp } \\
\text { Direction }\end{array}$ & 0.088002 & 0.093058 & 0.090865 \\
& & & \\
\hline $\begin{array}{l}\text { Fill } \\
\text { Direction }\end{array}$ & 0.115699 & 0.141413 & 0.096420 \\
\hline
\end{tabular}




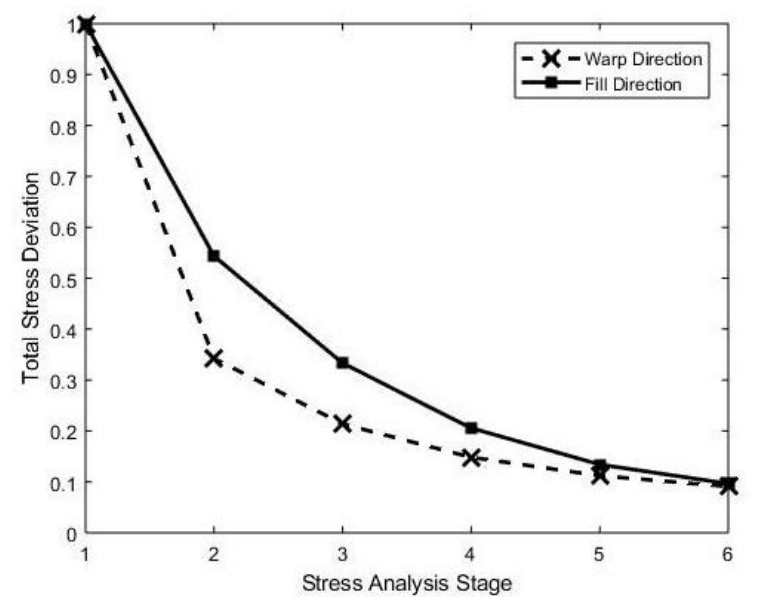

Fig. 5. Total stress deviation versus stress analysis stage of Model III.

The corresponding values of least square error obtained in the table for stresses in warp and fill direction are significantly larger than the tolerance of 0.01 as adopted in this study. Such significance is due to the characteristics of Costa minimal surface that does not have any boundary and assumptions have been made of the boundary as explained by [1]. The shape obtained after form-finding is close to the initial assumed shape of half-Costa model in YZ-plane.

\section{CONCLUSION}

Form-finding of half-Costa TMS model in YZ-plane with different boundaries have been carried out successfully using nonlinear analysis method. The results proved that all models presented are structurally viable surface form to be considered. Portion of the Costa minimal surface in Model I, II and III have the potential to be applied to form of TMS, creating a unique structural form. It can be considered as a sustainable development for the green environment and technology, it also can be used to support the effectiveness used of energy and the structure.

\section{CONFLICT OF INTEREST}

The authors declare no conflict of interest.

\section{AUTHOR CONTRIBUTIONS}

YHM is responsible for the conception and design of this study. The model generation, data analysis and interpretation are done by NAAM. HMA draft the article and critical revision of the work. Finally, the article is approved by HYM to be published.

\section{ACKNOWLEDGMENT}

The researchers wish to thank to Universiti Teknologi MARA, Cawangan Pulau Pinang for the administrative support.

\section{REFERENCES}

[1] H. M. Yee, "A computational strategy for form-finding of tensioned fabric structures using nonlinear analysis method," $\mathrm{PhD}$ Thesis, Universiti Sains Malaysia, School of Civil Engineering, Nibong Tebal, 2011.
[2] Task Committee on Tensioned Fabric Structures, "Tensile fabric structure: Design, analysis, and construction," Reston, Virginia, United States of America: American Society of Civil Engineers, 2013.

[3] B. Philipp, R. Wüchner, and K. U. Bletzinger, "Advances in the form-finding of structural membranes," Procedia Engineering, vol. 155,2016 , pp. 332-341.

[4] J. Lipkovski and A. Lipkovski, "Form-finding software and minimal surface equation: A comparative approach," Filomat, vol. 29, 10, 2015 , pp. 2447-2455.

[5] H. M. Yee, K. K. Choong, and J. Y. Kim, "Form-finding analysis of tensioned fabric structures using nonlinear analysis method," Advanced Materials Research, 2011, pp. 1429-1434.

[6] H. M. Yee, J. Y. Kim, and M. M. Noor, "Tensioned fabric structures in oval form," Applied Mechanics and Materials, vol. 405-408, 2013, pp. 1008-1011.

[7] M. M. Noor, H. M. Yee, K. K. Choong, and H. A. Hamid, "Tensioned membrane structures in the form of egg shape," Applied Mechanics and Materials, 2013, pp. 989-992.

[8] H. M. Yee and K. K. Choong, "Form-finding of tensioned fabric structure in the shape of möbius strip," Iranica Journal of Energy \& Environment 4 \{(3) Geo-hazards and Civil Engineering)\}, 2013, pp. 251-257.

[9] H. M. Yee and M. A. Samsudin, "Development and investigation of the Moebius Strip in tensioned membrane structures," WSEAS Transactions on Environment and Development, vol. 10, 2014, pp. 145-149.

[10] H. M. Yee and M. A. Samsudin, "Mathematical and computational Analysis of moebius strip," International Journal of Mathematics and Computers in Simulation, vol. 8, 2014, pp. 197-201.

[11] H. M. Yee, H. A. Hamid, and M. A. Hadi, "Computer investigation of tensioned fabric structure in the form of Enneper minimal surface," Applied Mechanics and Materials, 2015, pp. 743-746.

[12] H. M. Yee, K. K. Choong, and M. A. Hadi, "Sustainable development of tensioned fabric green structure in the form of Enneper," International Journal of Materials, Mechanics and Manufacturing, vol. 3, no. 2, 2015, pp. 125-128.

[13] H. M. Yee and M. A. Hadi, "Tensioned fabric structures with surface in the form of Chen-Gackstatter and Monkey Saddle," International Journal of Structural and Civil Engineering Research, vol. 4, no. 4, 2015, pp. 331-335.

[14] M. A. Hadi, H. M. Yee, K. A. Ghani, and H. A. Hamid, "Architectural tensioned fabric structure in Monkey Saddle form," International Journal of Control Theory and Applications, vol. 9, no. 6, 2016, pp. 2753-2758.

[15] M. H. W. Ibrahim, M. N. A. Hadi and H. M. Yee, "Form-finding using nonlinear analysis method in tensioned fabric structure in the form of handkerchief surface," Journal of Physics, vol. 995, 2018, pp. 1-9.

[16] H. M. Yee, A. P. Norman, A. Azura, N. Hamzah, N. I. Zainuddin, and M. I. F. Rozli, "Computational form-finding analysis in the shape of bour's," WSEAS Transactions on Applied and Theoretical Mechanics, vol. 13, 2018, pp. 140-149.

[17] M. H. W. Ibrahim, M. N. A. Hadi, and H. M. Yee, "Form-finding of thomsen surface using nonlinear analysis method," Journal of Physics, vol. 995,2018 , pp. 1-8.

[18] H. M. Yee and M. N. A. Hadi, "Form-finding with and without cable reinforced thomsen surface in tensioned fabric structure," Journal of Physics, vol. 1174, 2019, pp. 1-7.

[19] A. Fomeko, "Minimal surfaces: Embarking on a plane discussion," ProQuest Education Journals, pp. 4-13, 2000.

[20] N. E. A. Cunningham, "Variational approach to the local uniqueness of minimal surfaces immersed in R(3)," Computational and Applied Mathematics, Houston, Texas: A Bell \& Howell Information Company, 1998.

[21] E. Weisstein, MathWorld, 2017.

[22] R. Wagner, Kinematics in Tensioned Structures, Dordrecht: Springer Netherlands, 2008

[23] H. M. Yee and K. K. Choong, "A computational mechanics using nonlinear analysis method in tensioned fabric structures," International Journal of Mechanics, vol. 10, 2016, pp. 261-265.

Copyright (C) 2020 by the authors. This is an open access article distributed under the Creative Commons Attribution License which permits unrestricted use, distribution, and reproduction in any medium, provided the original work is properly cited (CC BY 4.0). 




Hafizah Muhamad Azlan was born on the $25^{\text {th }}$ December 1986 at Bota, Perak, Malaysia. She graduated with the master of civil engineering (2013), the bachelor of engineering (Hons) civil (2009) and diploma in civil engineering (2006) from the Universiti Teknologi MARA, Shah Alam, Selangor, Malaysia. After graduating, she worked as lecturer at Faculty of Civil Engineering, Universiti Teknologi MARA, Pulau Pinang, Malaysia and was promoted to senior lecturer on January 2019.

Her research interested in structure and materials that related to civil engineering such as steel structure, fabric structure, composite material, concrete, timber engineering and finite elements. She also member of board of engineering Malaysia.

Mrs. Hafizah obtained 8 award in Invention, Innovation and Research Design platform where contribute to 2 Gold award, 5 Silver award and 1 Bronze award. She has published in several journal and proceeding along her carrier.

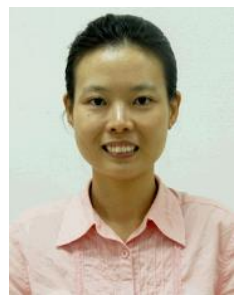

Yee Hooi Min was born on the $16^{\text {th }}$ March 1981 a Sungai Petani, Kedah, Malaysia. She graduated with a doctorate degree structural engineering, master of science engineering and bachelor of engineering (Honours) civil engineering from the Universiti Sains Malaysia, Pulau Pinang, Malaysia. She was a fellow at Universiti Sains Malayisa. After graduating, she worked as senior lecturer at Faculty of Civil Engineering, Universiti Teknologi MARA, Pulau Pinang, Malaysia and was promoted to Associate Professor on 2017. Her research interest is Computational Mechanics, Computational Analysis of Shell and Spatial Structures, Nonlinear Analysis, Engineering Education and Architectural Engineering. She is a supervisor of PhD and Master students. She is an external examiner for the postgraduate student.

She is also certified as an 'International Professional Engineer', 'APEC Engineer', 'ASEAN Engineer', Professional Engineer with Practising Certificate of Board of Engineers Malaysia, Corporate Member of The Institution of Engineers Malaysia, The ASEAN Federation of Engineering Organisations, Construction Industry Development Board Malaysia and Concrete Society of Malaysia.

She is an evaluation panel Engineering Accreditation Council and Engineering Technology Accreditation Council. She is a Professional
Engineer Interviewer/Examiner for The Institution of Engineers Malaysia since 2016. She is an Executive Committee of The Institution of Engineers Malaysia (Penang Branch) from 2014-16 and 2017-2019. For her much appreciated leadership and contributions towards excellence in engineering, society enhancement and nation development; the international Engineering Fraternity conferred Associate Professor Ir. Dr. Yee the ASEAN Federation of Engineering Organisations (AFEO)'s Honorary Member Award by AFEO Governing Board which carries the abbreviation M.AFEO after her name on 2018. She conferred the status of International Professional Engineer and APEC Engineer by EMF International Professional Engineer and Asia-Pacific Economic Cooperation, respectively on 23 November 2017 together with the designatory letters IntPE and APEC ENGINEER. She conferred ASEAN Engineer award by the AFEO Governing Board together with the designatory letters ASEAN Eng. on 2015. She is awarded Universiti Teknologi MARA 'Excellent Service Award'. She as a vice-chairman for the 2 international conference have been held in Malaysia on 2015. She is The Conference of the ASEAN Federation of Engineering Organisations (CAFEO) organizer committee on 2015. She has organized a technical visit to South Korea and Russia on 2016 and 2018, respectively under Women Engineers Section in IEM (Penang branch). She is an earthquake design sub-committee from IEM (Penang branch) on 2019.

Associate Professor Ir .Dr. Yee has obtained 16 awards in Invention, Innovation and Research Design Platform and has published 86 up-to-date publications. Her other achievements include invitations as Keynote Speaker, International Invited Speaker, International Visiting Professor, Session Chairman and technical committee to over international and national technical conferences and seminars worldwide which include those in Czech Republic, United Kingdom, Ireland, Spain, Australia, Republic of China Indonesia, Thailand and Malaysia.



Nurul Afiqah Abd Malek was born on the $17^{\text {th }}$ October 1991 at Penang, Malaysia. She graduated with the bachelor of engineering (Hons) (infrastructure) (2016) and diploma in civil engineering (2013) from Universiti Teknologi MARA, Cawangan Pulau Pinang, Malaysia.

Currently she is doing the master of civil engineering at Universiti Teknologi MARA, Cawangan Pulau Pinang, Malaysia. 